\title{
First trimester prenatal diagnosis of Menkes disease by DNA analysis
}

\author{
Zeynep Tümer, Tønne Tønnesen, Johann Böhmann, Wolfgang Marg, Nina Horn
}

\begin{abstract}
Menkes disease is an $\mathrm{X}$ linked recessive disorder of copper metabolism characterised by neurological symptoms and connective tissue manifestations. The defective gene in Menkes disease has recently been isolated and the gene product is predicted to be a copper transporting ATPase. The diagnosis of Menkes disease has hitherto been performed by biochemical analysis, based on intracellular accumulation of copper. Cloning the gene opened up the possibility of establishing precise and reliable carrier and prenatal diagnosis by defining the molecular defect. In this report we describe the partial deletion of the Menkes gene in a patient who had inherited the mutation from his phenotypically normal mother. This information enabled us to perform prenatal diagnosis by direct mutation analysis of the mother's sixth pregnancy and we detected the same deletion, indicating that the male fetus was affected. This first prenatal diagnosis of Menkes disease by direct mutation analysis shows some advantages of DNA analysis compared to biochemical diagnosis.
\end{abstract}

( $(\mathcal{F}$ Med Genet 1994;31:615-617)

Menkes disease is an $\mathrm{X}$ linked recessive disturbance of copper metabolism mainly characterised by peculiar hair, connective tissue manifestations, and progressive psychomotor retardation, leading to death in early childhood. Most of the clinical symptoms can be explained by malfunction of one or more of the known copper requiring enzymes, indicating deficiency of an intracellular copper transport protein. ${ }^{1}$ The Menkes locus has been mapped to $\mathrm{Xq13.3^{2 }}$ and the gene defective in Menkes disease has recently been isolated by three different groups including ours. ${ }^{3-5}$ On the basis of nucleotide sequences the protein is predicted to encode a copper transporting ATPase and the $5^{\prime}$ end contains six putative metal binding sites, supporting the copper transport defect in Menkes disease.

To date the only definitive diagnosis of Menkes disease has been by biochemical analysis, based on intracellular accumulation of copper owing to impaired outflow. Prenatal diagnosis in the first trimester has been performed by measuring copper in chorionic villi, a test very susceptible to exogenous copper contamination. Carrier diagnosis by measuring ${ }^{64} \mathrm{Cu}$ uptake in cultured fibroblasts is possible, but not reliable in all cases owing to random inactivation of one of the $\mathrm{X}$ chromosomes. Furthermore, biochemical analysis is only performed in a few centres in the world. To establish a means of precise, easy, and reliable carrier and prenatal diagnosis as well as to determine the genotype-phenotype correlation, we started defining the lesions disrupting the gene in about 230 Menkes patients referred to our institute since 1977 .

So far we have identified deletions and duplications/insertions of different sizes and localisations disrupting the Menkes gene in $\mathbf{4 0}$ unrelated patients ${ }^{4}$ (unpublished data) with Southern blot hybridisations using cDNA and genomic probes. ${ }^{4}$ In $75 \%$ of these patients we detected an altered band pattern, which could be used in determining the carrier status. ${ }^{6}$ In these cases we investigate all the available female family members for possible carrier status, to be able to perform a subsequent prenatal diagnosis by DNA methods.

In this report we describe the genetic lesion in a Menkes family, where we performed the first prenatal diagnosis by direct mutation analysis, and show some advantages of DNA analysis compared to biochemical diagnosis.

\section{Materials and methods}

CLINICAL REPORT AND FAMILY HISTORY

The index patient was the first child of unrelated healthy parents. He had typical clinical features of Menkes disease including psychomotor retardation, muscular hypotonia, feeding difficulties, dry and loose skin, and abnormal hair. Tonic-clonic seizures began at the age of 4 months and could not be controlled with antiepileptic therapy. EEG showed multifocal seizure activity and on nuclear magnetic resonance scan slight cerebral atrophy and distension of the inner cerebral cavities were observed. Low levels of serum copper (2.1 $\mu \mathrm{mol} / 1, \quad \mathrm{n}=11-25)$ and caeruloplasmin $(0.11 \mathrm{~g} / \mathrm{l}, \mathrm{n}=0.15-0.60)$ and increased ${ }^{64} \mathrm{Cu}$ uptake in cultured fibroblasts $\left(60.6 \mathrm{ng}{ }^{64} \mathrm{Cu} / \mathrm{mg}\right.$ protein/20 hours, control range 7.4-25.0) confirmed the clinical diagnosis. Cu-histidine and penicillamine treatment was not effective and the child died at the age of 17 months from pneumonia. Cytogenetic analysis did not show any visible deletion of chromosome material. ${ }^{64} \mathrm{Cu}$ uptake values of the phenotypically normal mother were higher than normal $(51.2 \mathrm{ng}$ ${ }^{64} \mathrm{Cu} / \mathrm{mg}$ protein $/ 20$ hours, control range $11 \cdot 1-$ 26.7) indicating that she was a carrier.

In the mother's second pregnancy, copper studies on chorionic villi (18.1 ng copper $/ \mathrm{mg}$ $w w$, controls $(n=50) 0.3-1 \cdot 2)$ indicated an affected male fetus. The copper content of chorionic villi taken at termination was, however, normal (1.25 ng copper/ng ww) and 
copper uptake into cultured fetal fibroblasts gave conflicting results leaving the final diagnosis unresolved.

In her third pregnancy prenatal diagnosis by measuring copper in chorionic villi also indicated an affected male fetus ( $7 \cdot 5 \mathrm{ng}$ copper $/ \mathrm{mg}$ ww) and the pregnancy was terminated. The prenatal diagnosis was confirmed by measuring the copper content in kidney from the formalin fixed fetus (6.44 ng copper/mg ww, control range $0 \cdot 52-1 \cdot 9$ ). Following these pregnancies the mother gave birth to two phenotypically normal girls.

The mother had four sisters and six brothers. Two sisters have one healthy son each and three brothers have died in early infancy without a diagnosis.

\section{DNA ANALYSIS}

Genomic DNA was prepared from chorionic villi or cultured fibroblasts. HindIII or EcoRI digested DNA fragments were separated through a $0.7 \%$ agarose gel, Southern blotted, and analysed by hybridising ${ }^{7}$ with genomic $(0.35 \mathrm{~kb} 1-1)$ or cDNA $(1.4 \mathrm{~kb}$ cMNK1 and $0.35 \mathrm{~kb}$ cMNK3) probes (fig 1). The cDNA probes are overlapping and they represent at least five exons in the $5^{\prime}$ putative metal binding end of the Menkes gene. ${ }^{4}$ cDNA probes together with the more distal genomic probe (1-1) detect a genomic region of $48 \mathrm{~kb}$ representing at least eight exons (unpublished results) (fig 1).

Measurement of ${ }^{64} \mathrm{Cu}$ uptake in cultured fibroblasts and copper content in chorionic villi were performed as previously described. ${ }^{8}$

\section{Results and discussion}

The diagnosis of Menkes disease was established clinically and biochemically in the first child of the family, and following the isolation of the Menkes gene we could describe the underlying molecular defect. DNA analysis of the proband showed a partial deletion in the $5^{\prime}$ metal binding end of the Menkes gene (fig 1). When the cDNA probe $\mathrm{cMNK} 3$ was hybridised against the EcoRI and HindIII digests of the patient's DNA, all the normal bands were shown to be deleted (results not

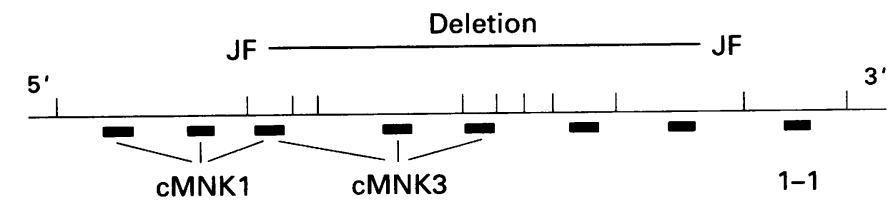

$\overline{5 b}$

Figure 1 Organisation of the 5' end of the Menkes gene and the spectrum of the molecular defect in the family. $\mathfrak{F F}=$ junction fragment. Black boxes indicate exons. shown). The cDNA probe $\mathrm{cMNK} 1$ detected an altered sized band, instead of the normal band, with HindIII digests (fig 2). The genomic probe 1-1 also detected an abnormal fragment instead of the normal one with EcoRI digests (results not shown). By detecting the junction fragments at both ends, we could confine the deletion to an approximately $25 \mathrm{~kb}$ genomic fragment. According to our unpublished results, this fragment represents five exons and four putative metal binding sites at the $5^{\prime}$ end of the gene (fig 1). DNA analysis of the mother confirmed her carrier status, indicated by an altered sized band in addition to a normal band representing the normal $\mathrm{X}$ chromosome. These findings enabled us to perform prenatal diagnosis in her present (sixth) pregnancy by means of DNA analysis in parallel with the biochemical analysis. The presence of the same mutation indicated that the male fetus was affected and the family decided to terminate the pregnancy. The high copper value in chorionic villi ( $6.5 \mathrm{ng}$ copper $/ \mathrm{mg} \mathrm{ww}$ ) was in concordance with this result. The diagnosis was confirmed after termination of the pregnancy by a high placental copper value and increased copper incorporation in cultured fetal fibroblasts.

This study illustrates some advantages of DNA analysis compared to biochemical analysis, which has hitherto been the only definitive diagnostic test. Biochemical diagnosis of Menkes disease is based on intracellular accumulation of copper owing to impaired outflow. First trimester prenatal diagnosis is carried out by measuring copper in chorionic villi. As the normal copper content in this tissue is very low ( $1 \mathrm{ng}$ copper per mg tissue), the test is highly susceptible to exogenous copper contamination, which could easily produce false positive results. The whole procedure of chorionic villi sampling must therefore be absolutely free of copper contamination, but as the samples are normally processed locally at the time of sampling, though rare,

Figure 2 Southern blot analysis. The DNA was digested with HindIII and hybridised with the $c D N A$ probe cMNK1. The approximately $23 \mathrm{~kb}$ junction fragment

(indicated by arrow) can

be seen both in the

proband (II.1), the

present (sixth) pregnancy

(II.3), and the carrier

mother (I), who also

shows the $10 \mathrm{~kb}$ normal

band, representing the

normal $X$ chromosome.

The male fetus of her

second terminated

pregnancy (II.2), shows a

normal band pattern,

indicating that he was not

affected. This analysis

also shows clearly that

chorionic villi (II.2, II.3)

were not contaminated by

maternal tissue.

$C=$ control . 
this condition is not always fulfilled, so that in such cases DNA analysis becomes especially important. When the separation of maternal tissue from the chorionic villi is not optimal, this may also be a source of false positive or false negative results in biochemical analysis. DNA analysis is therefore very useful in determining the presence of maternal tissue (fig 2). In the mother's second pregnancy the contradictory results could not be explained by exogenous copper contamination or ineffective separation of the maternal deciduum. The copper follow up studies did not clarify the diagnosis, but the DNA studies allowed a decisive diagnosis and showed that the aborted male fetus was normal. Introduction of DNA analysis will therefore be beneficial especially in first trimester diagnosis of Menkes disease. Since 1983, 116 first trimester prenatal diagnoses in male fetuses at risk have been carried out at The John F Kennedy Institute using copper analyses. Even though the overall accuracy of diagnosis by biochemical studies is 98 to $99 \%$, there have been 16 problematical cases, where DNA analysis would have been of great value (manuscript in preparation).

Until now biochemical tests for pre- and postnatal and carrier diagnoses of Menkes disease could only be accomplished in a few laboratories in the world. DNA based analysis will thus allow the diagnosis of Menkes disease to be made in any laboratory with DNA analysing facilities.

In the present case, ${ }^{64} \mathrm{Cu}$ uptake value of the mother was within the previously described range for female Menkes carriers, ${ }^{9}$ and the molecular analysis confirmed her carrier status. As copper uptake analysis depends on gene expression and may not be informative for carrier diagnosis owing to random $\mathrm{X}$ inactivation, molecular analysis will provide the means of a more precise and reliable carrier diagnosis. ${ }^{6}$

Three maternal uncles of the index patient died in early infancy without a diagnosis, suggesting that they might have been affected. As the mother's carrier status has now been determined, it is likely that this partial deletion of the Menkes gene in one of her X chromosomes was inherited from her mother. This knowledge opens up the possibility of investigating other female members of the family for carrier status.

The role of molecular genetic approaches in diagnostic medicine have been increasing rapidly in recent years. By providing means of a reliable and precise carrier and prenatal diagnosis of Menkes disease, DNA analysis will benefit both clinicians and families. Establishment of the exon-intron structure of the Menkes gene will enable a PCR based analysis which will also accelerate the diagnosis.

We acknowledge Drs Anthony P Monaco and Jamel Chelly for collaboration in cloning the Menkes gene, which made this study possible. Karen Friis-Henriksen and Annie Levin Larsen are thanked for their technical assistance. ZT is supported by Fellowship 42-2901 from the Danish Research Academy. Thi study was supported by The Danish Medical Research Counsil (12-0058, 12-9292, 12-9744 and 12-1450) The Danish Bio(12-0058, 12-9292, 12-9744, and 12-1450), The Danish Biotechnological Research and Development Programme 1991Foundation (H 11/210-89, H 11/282-90, and H 11/257-91).

1 Horn N, Tonnesen T, Tümer Z. Menkes disease: an Xlinked neurological disorder of the copper metabolism Brain Pathol 1992;2:351-62.

2 Tümer Z, Horn N, Tønnesen T, Tommerup N. Mapping of the Menkes locus to Xq13.3 distal to the X-inactivation center by an intrachromosome insertion of the segment Cq13.3-q21.2. Hum Genet 1992;88:668-72.

3 Vulpe C, Levinson B, Whitney S, Packman S, Gitschier J Isolation of a candidate gene for Menkes disease and evidence that it encodes a copper-transporting ATPase. Nature Genet 1993;3:7-13.

4 Chelly J, Tümer Z, Tønnesen $\mathrm{T}$, et al. Isolation of a candidate gene for Menkes disease that encodes for a potential heavy metal binding protein. Nature Genet 1993;3:14-19.

5 Mercer JFB, Livingston J, Hall B, et al. Isolation of a partial candidate gene for Menkes disease by positional cloning. Nature Genet 1993;3:20-5.

6 Tümer Z, Tønnesen T, Horn N. Detection of genetic defects in Menkes disease by direct mutation analysis and its implication in carrier diagnosis. $\mathcal{f}$ Inher Metab Dis (in press).

7 Maniatis T, Fritsch E, Sambrook J. Molecular cloning: a laboratory manual. Cold Spring Harbor: Cold Spring Harbour Laboratory Press, 1982.

8 Tønnesen T, Horn N. Prenatal and postnatal diagnosis of Menkes disease, an inherited disorder of copper metabolMenkes disease, an inherited disorder of copper
ism. F Inher Metab Dis 1989;1(suppl 12):207-14.

ism. F Inher Metab Dis 1989;1(suppl 12):207-14.
9 Horn N. Menkes' X-linked disease: prenatal diagnosis and

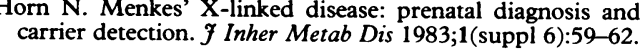

